\title{
So many tuhao and dama in China today
}

\author{
MINGWU XU AND CHUANMAO TIAN
}

\author{
The latest developments in China English vocabulary based \\ on the China Daily website
}

\section{Introduction}

The last three decades have witnessed an increase in the number of middle-class people in China. Some of them spend money like water, have garish tastes and lack 'good' cultural traits and sophistication; they are called tuhao in Chinese (Cai, 2014). Others, in particular most of the middle-aged women, who are called dama, 'live a happy life with plenty of free time and money', investing in gold, bitcoins and overseas property markets and enjoying noisy square dances. (dama is a term coined by The Wall Street Journal) (Zhou \& He, 2015). It was rumored around the end of 2013 that Chinese words, such as tuhao, dama and hukou 'household registration' would enter into the Oxford English Dictionary (Gui, 2013), which was still not the case when we searched the online Oxford Dictionaries for these words in 2015 (oxforddictionaries.com, 2015).

In fact, these words do exist in a variety of English, namely China English, whose existence or prospective appearance has been acknowledged by some researchers (Eaves, 2011; Bolton \& Graddol, 2012; Botha, 2014; Hu, 2016). China English, or Chinese English, refers to 'English with Chinese characteristics' (Pinkham, 2000). It is closely associated with the use of Chinese words that have been translated literally into English. At present, English is extensively used in China in many areas, including education, foreign publicity, tourism and intercultural communication. The rapid development of the country has given rise to many new social, economic and cultural phenomena, which is perhaps the main reason for the appearance of many Chinese neologisms and buzzwords.

The present study aims to explore what semantic domains neologisms in China English Vocabulary
(CEV) belong to, how they have been produced in recent years, what grammatical and morphological forms they have and why they have these forms. We hypothesize that the new members in CEV are semantically closely related to traditional

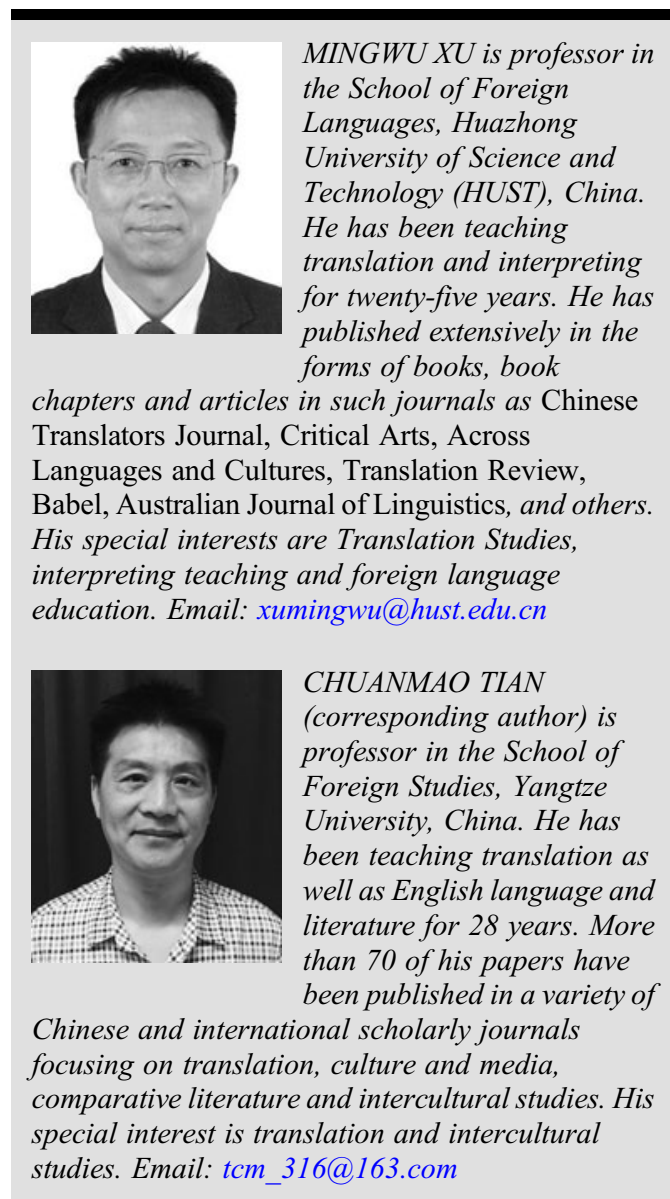


culture, government policy and social phenomena; they are mainly derived from Chinese neologisms and buzzwords via a few translating methods, especially transliteration, and their forms are influenced by Chinese structure. In the following sections we first introduce the methodology of this study, then discuss the semantic domains and forms of neologisms in CEV, and finally explore the reasons and problems related to the forms of the neologisms.

\section{Research methodology}

The data for this project is taken from three sources: (1) Report on the Language Situation in China issued by the State Ministry of Education and the State Language Committee; (2) the Top 10 Buzzwords of Yaowen Jiaozi, an authoritative journal on Chinese words; (3) the 'Neologisms and translations' list from the China Daily website. The reason why we chose this website (chinadaily. com.cn) as one of the sources of data is that it is arguably China's most influential English-language web portal (Du \& Zhang, 2012), and that its main newspaper, China Daily, has a great impact on domestic English learners and users and even on foreign media and readers, particularly with respect to the use of Chinese-specific words (Qiu, 2014).

The China Daily website, together with its 'Neologisms and translations' list, ${ }^{1}$ serves as a corpus to study CEV because it provides a search function for English words on its homepage (Figure 1). The search results webpage provides varied information on the searched word, i.e. number of texts, types of text, title and text string in which the searched word is highlighted in the red color.

By entering the English translations of ten representative Chinese neologisms and buzzwords (i.e. the Top 10 Buzzwords of Yaowen Jiaozi) in the search box on the China Daily website on the $18^{\text {th }}$ April, 2016, we obtained their raw frequencies
(Table 1). The abbreviations in Table 1 refer to transliteration ( $\mathrm{T}$ ) such as 'shanzhai' (山寨), literal translation (LT) such as 'mountain fortress' (山寨), transliteration and literal translation $(\mathrm{T}+\mathrm{LT})$ such as 'hongbao, red envelopes' (红包), free translation (FT) such as 'dregs of society' (屌丝), transliteration and free translation $(\mathrm{T}+\mathrm{FT})$ such as 'yuesao, or confinement nannies' (月嫂) and literal translation and free translation (LT+FT) such as 'human flesh search - a massive cyber manhunt' (人肉搜索).

The analysis of the semantic domains of neologisms in CEV was based on the 'Neologisms and translations' list which presents the translations in alphabetical order and bilingual correspondence. We chose ten representative transliterations from the Top 10 Buzzwords of Yaowen Jiaozi between 2008 and 2015 and the 'Neologisms and translations' list. We obtained the sample sentences in which they are used on the website (partly represented in Figure 1). Then, we analyzed their morphological and grammatical properties. Finally, we explored the reason why the translations of Chinese neologisms and buzzwords take the forms they do.

\section{Semantic domains of neologisms in CEV}

China's fast development in the last decade has produced many neologisms and buzzwords. They can roughly be divided into the following three categories, i.e. social life, government policy and traditional culture. The CEV related to social phenomena generally embraces hot societal issues and events of top concern. For example, the widespread existence of fake products in the country gives rise to shanzhai; the awfully high housing prices turn many Chinese into mortgage slaves who have to work hard all their life to repay the mortgage. The huge gap between the poor and the rich has produced a large group of young men, namely

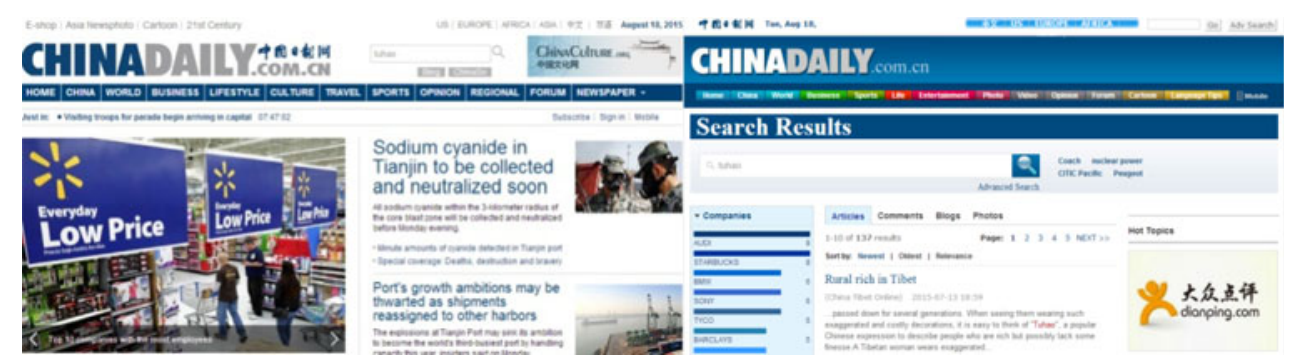

Figure 1. China Daily homepage and search results webpage 


\begin{tabular}{|c|c|c|c|c|c|c|}
\hline Type of Translation Neologism & $T$ & LT & $\mathrm{T}+\mathrm{LT}$ & $\mathrm{FT}$ & $\mathrm{T}+\mathrm{FT}$ & $\mathrm{LT}+\mathrm{FT}$ \\
\hline 山寨‘fake’ & 236 & 0 & 3 & 0 & 51 & 0 \\
\hline 不折腾 'no trouble-making' & 5 & 0 & 0 & 0 & 2 & 0 \\
\hline 给力 'give power' & 73 & 0 & 0 & 0 & 27 & 0 \\
\hline 城管 'urban patrol officer' & 896 & 0 & 0 & 0 & 642 & 466 \\
\hline 屌丝‘dregs of society’ & 59 & 0 & 0 & 19 & 26 & 0 \\
\hline 围脖 ‘microblog’ & 14,730 & 3,357 & 1,711 & 0 & 0 & 0 \\
\hline 高富帅 ‘rich, tall, handsome’ & 2 & 77 & 2 & 0 & 0 & 0 \\
\hline 土豪 ‘nouveau riche' & 138 & 0 & 3 & 804 & 42 & 0 \\
\hline 大妈 ‘middle-aged woman’ & 393 & 0 & 0 & 0 & 158 & 0 \\
\hline 正能量 ‘positive energy' & 4 & 7,456 & 4 & 0 & 0 & 0 \\
\hline
\end{tabular}

diaosi who come from poor families, lack social privileges and complain about the current social order. The overcrowding in the Spring Festival travel rush creates chunyun.

As for government policy, the guidelines of the Communist Party of China and the regulations and targets of the Central Government are another contributor to the creation of neologisms and buzzwords, such as xiaokang society, all-round well-off society, Three Represents, scientific outlook on development, eight honors and eight disgraces, Belt and Road Initiative, new normal, inclusive growth, housing allowance, independent recruitment, tax-for-fee, bunker adjustment factor, attract investment from overseas and bear and rear better children. Traditional culture also lends some words to the contemporary CEV. A case in point is Bagua, whose original meaning is 'eight diagrams' but which has been given a new sense, 'gossip', in the new century. Other Chinese culture-specific expressions include reganmian 'Wuhan noodle snack', China's Time-Honored Brand, Chinese knot, yangchunmian 'plain noodle', eight-treasure rice pudding, witty skits, courtyard dwelling, six classical arts, orchid fingers, pay a New Year's visit, assign priority according to seniority, and so on.

\section{Forms of CEV}

As far as the perspective of translation is concerned, there are several methods to produce CEV. It seems that transliteration or Romanization of Chinese words has been a striking phenomenon in the most recent few years for CEV building (see Table 1). Tuhao (土豪, /tuhao/) and dama (大妈, /dama/) are among the most famous examples. This method, which uses the phonetic alphabet to transcribe Chinese characters, may be called the Chinese pinyin method (He \& Xiao, 2003). Transliterations of Chinese words and expressions are frequently used in China English (Table 2). The ten words in Table 2 are among the Top 10 Buzzwords of Yaowen Jiaozi between 2008 and 2015, and thus they are arguably the best representatives of neologisms in CEV. It is assumed that the reliability of the data related to the grammatical and morphological forms such as 'inflection' and 'derived form' in Table 2 is restricted to the data collected from the website.

As shown in Table 2, the form of almost all transliterations, or pinyin versions of Chinese words, is fixed without any inflection. For example, verbs do not have tense markers, as in People's Daily's heading 'Jiangsu Province Geili A Strong Cultural Province' in which geili as a verb retains its root form without a conjugation, such as $-s$ or $-e d$. As for nouns, there is no distinction between their singular and plural forms. In other words, the singular form of count nouns can express the plural meaning. For example:

(1) The wealthy man, called a tuhao (newly rich) by netizens, said on the Twitter-like micro blog that he is offering 1 million yuan to accompany him back home in Shenzhen city during the festival.

(2) Among China's 'tuhao', or those with loads of cash but no class (or the nouveaux riches), the lust for gilt-edged items goes beyond 
Table 2: Ten transliterated Chinese words

\begin{tabular}{|c|c|c|c|c|c|}
\hline $\begin{array}{l}\text { Chinese } \\
\text { words }\end{array}$ & $\begin{array}{l}\text { Chinese } \\
\text { pinyin } \\
\text { version } \\
\end{array}$ & \multicolumn{3}{|c|}{ Grammatical and morphological forms } & \multirow[t]{2}{*}{ English interpretations } \\
\hline & & Inflection & $\begin{array}{l}\text { Part of } \\
\text { speech }\end{array}$ & $\begin{array}{l}\text { Derived } \\
\text { form }\end{array}$ & \\
\hline 土豪 & tuhao & $x$ & $\begin{array}{l}\text { noun, } \\
\text { adjective }\end{array}$ & $x$ & nouveau riche, vulgar rich \\
\hline 大妈 & dama & $\times$ & noun & $x$ & middle-aged women \\
\hline 山寨 & shanzhai & $x$ & $\begin{array}{l}\text { noun, } \\
\text { adjective }\end{array}$ & post-shanzhai & $\begin{array}{l}\text { mountain fortress, } \\
\text { copycat, fake goods }\end{array}$ \\
\hline 屌丝 & diaosi & $x$ & noun & $x$ & $\begin{array}{l}\text { underprivileged losers, } \\
\text { dregs of society }\end{array}$ \\
\hline 给力 & geili & $x$ & $\begin{array}{l}\text { verb, } \\
\text { adjective }\end{array}$ & $\begin{array}{l}\text { (un) } \\
\text { geili-vable }\end{array}$ & $\begin{array}{l}\text { give power, giving } \\
\text { strength, great, cool, } \\
\text { awesome, exciting }\end{array}$ \\
\hline 红包 & hongbao & $\times$ & noun & $x$ & $\begin{array}{l}\text { red envelopes containing } \\
\text { money }\end{array}$ \\
\hline 农民工 & $\begin{array}{l}\text { nongmin } \\
\text { gong }\end{array}$ & $\times$ & noun & $x$ & $\begin{array}{l}\text { migrant workers, farmer } \\
\text { workers }\end{array}$ \\
\hline 城管 & chengguan & $x$ & noun & $x$ & urban patrol officers \\
\hline 月嫂 & yиesao & $x$ & noun & $x$ & $\begin{array}{l}\text { confinement nurse, } \\
\text { confinement nannies }\end{array}$ \\
\hline 春运 & chunyun & $x$ & noun & $x$ & Spring Festival travel rush \\
\hline
\end{tabular}

bathroom fixtures to include underwear and shoes, as well as 18 -carat gold mobile devices costing $\$ 5,513$ to $\$ 6,282$.

Examples (1) and (2) indicate that tuhao can be used to express singular and plural meanings. The formal stability of the transliterations also lies in their low productivity, whereby just a few of them have a derived form. For example:

(3) This innovative electric car and battery producer signifies China's shift to 'indigenous innovation' in a 'post-shanzhai era', Xinhua reports.

(4) Yang Changyou, a household service shop owner, rests in a chair with a board hanging on the back saying 'Nannies in urgent need, salary is geilivable', in Hangzhou, East China's Zhejiang province, Dec 20, 2010.

(5) In the last part of our three-part series, we take a look at some service-oriented apps used during this year's e-hongbao campaign.

As far as parts of speech are concerned, most transliterations of Chinese words are nouns and a small number of them can be used as an adjective and occasionally as a verb. As adjectives they are generally in the form of nouns, as illustrated in the following example:

(6) On his weibo micro blog, which has 12 million followers, Wang Jr. wrote that giving his dog four watches - one for each leg - 'seems much too tuhao (vulgar rich), so I kept it down to two'.

In example (6), the noun tuhao is directly used as an adjective with no declension. In fact, a few nominal transliterations can be put before other nouns as a pre-modifier, such as shanzhai product, tuhao gold and chunyun period in which shanzhai, tuhao and chunyun do not mean 'illegal and lowquality imitation', 'rich people with poor taste' and 'Spring Festival travel rush', but 'counterfeited', 'rich but vulgar' and 'pertaining to the Spring Festival travel rush', respectively. In this usage they convert from a noun to an adjective. A small number of transliterations can be put together with other words to form phrases, such as 
Chinese dama, weibo account, digital hongbao and Bagua boxing.

When the transliterations are used for the first time, they are paraphrased in some way. An appositive, a parenthesis and sometimes an attributive clause will be used to explain their meaning. Let us look at examples (7)-(14).

(7) The most popular is reganmian, hot dry noodles with a spicy flavor and a sesame paste dressing.

(8) It also is called gutter oil, digouyou, because sometimes restaurants discard their used oil into the streets and sewers, and that oil too is reclaimed and sold.

(9) Instead of hiring a yuesao, or postpartum care worker, she spent nearly 10,000 yuan $(\$ 1,600)$ on the United Family Home Health's postpartum service, which includes four visits from a midwife and two from a doctor within the first two weeks after being discharged from hospital.

(10) Thanks to a baby boom this year, the cost of hiring a confinement nurse, or yuesao in Chinese, can be more expensive than hiring a doctor.

(11) 'Each caregiver in our house needs to take care of about four disabled children at a slender monthly salary of about 1,200 yuan (\$195), but a yuesao, who takes care of the new-born baby and mother, in Nanchang earns about 5,000 yuan to 6,000 yuan a month,' she said.

(12) However, since the start of the millennium, hiring a yuesao (a stay-at-home care giver during the postpartum period) has become a common solution for families willing to pay.

(13) He is desperately seeking a qualified yuesao a sort of super-midwife - who will look after both mother and child in the first critical month after birth, but has so far met with no success.

(14) Much like the diaosi (帛丝) dregs of society, some 2B qingnian may wear the term with pride - often due to the same desire to stand apart from the masses, which is not so very different from the more sophisticated (though admittedly this is in the eye of the beholder) attempts by the wenqing.

Examples (7) and (8) show that the appositive paraphrase can be put after or before the transliterated word with a comma between them, while examples (9) and (10) indicate that, in some cases, the conjunction or may be used to introduce the paraphrase or the transliteration. In example (11), a nonrestrictive attributive clause is used to explain yuesao. Examples (12) and (13) show that the paraphrase can be put in parentheses or between dashes. In example (14), the transliterated word diaosi is first followed by the Chinese word 屌丝 in parentheses and then by an explanation. The meaning of some transliterations, such as tuhao, diaosi, geilivable and leiren, is greatly varied in different contexts. Tuhao has so far been paraphrased in the following ways: 'vulgar rich', 'nouveau riche', 'China's tacky nouveau riche', 'a new class of the lavishly rich and tasteless', 'rich people with ill manners', 'people who are rich but lack in education or taste', 'people who are rich but possibly lack some finesse', 'someone who has a lot of money but can't follow trends', and so on.

The above examples show that, in addition to transliteration, affixation is sometimes used together with transliteration to produce CEV, as illustrated by post-shanzhai and geilivable. The Urban Dictionary recorded two instances of Internet slang, i.e. zhuangbility and shability in which zhuangbi is the transliteration of the Chinese word 装逼; shabi is that of 俊逼; -ity is a nominal suffix (Chinadaily.com, 2014). These two informal vulgarisms express the abstract concepts of 'boastfulness' and 'foolishness', respectively.

Some other methods, such as literal translation, literal translation combined with transliteration, literal translation combined with free translation as well as free translation can also be used to form CEV. Regarding literal translation, a good case in point is 'nail household', which is the product of China's urbanization. In the process of urban construction, civilians' houses, in many cases, have to be demolished in order to provide enough space for public purposes. However, a few civilians refuse to move and bargain for unreasonably high governmental compensation. They are called 'nail households'. Here, nail is used metaphorically, implying that persuading the civilians to move to the designated place is as difficult as pulling out a nail fastened in something. Words of this kind include Vegetable Basket Project, Hope Project, positive energy, new normal, Three Represents, orange alert, mouse tribe, private home cuisine, half the sky, protective umbrella, capsule apartment, eight-treasure rice pudding, human flesh search, and so on.

Literal translation is sometimes used together with transliteration to create $\mathrm{CEV}$, as in xiaokang society in which xiaokang is the transliteration of the Chinese word 小康' meaning 'moderately well-off', and society is the literal rendering of 
社会. The Urban Dictionary recorded another example of this type, i.e. no zuo no die in which $z u o$ is the transliteration of the Chinese character 作 'do', and no and die are the literal renderings of 不 and 死, respectively (chinadaily.com, 2014). The whole expression 'no zuo no die means that 'if you do not do stupid things, they will not come back and bite you in the ass'. In some cases, both literal translation and free translation are employed to build CEV. For example, stall tea is the rendering of 大碗茶 in which tea is the literal translation of 茶 and stall is the free translation of 大碗' whose literal meaning is 'big bowl'. Examples of this category include material girl, match-making party, phone-in program, and so on. In many cases, Chinese words and phrases are translated freely, resulting in a complete loss of the original literal meaning. For example, absolute principle, top priority is the rendering of 硬道理 whose literal meaning is 'hard reason'. Sometimes a free translation can be lengthy in order to clarify the deep meaning of the Chinese word, as illustrated by the political term three direct links of trade, mail, and air and shipping services across the Taiwan Straits, which is actually an explanatory rendering of the Chinese abbreviation 三通 'three links'.

\section{Discussion and implications}

The latest developments in CEV have several characteristics. The neologisms mainly come from a few semantic domains, they are created via a few translating methods, and their forms are strongly affected by the Chinese language, which are discussed next.

As for the source of the latest CEV, most of the words are derived from the Internet and the media, such as the China Daily website on which neologisms are widely seen in articles, comments, blogs and photos. Some of them are not frequently used, such as no zuo no die. Others are intimately related to hot societal issues, government policy and Chinese culture, such as nail household, Three Represents and reganmian; a few are informal and vulgar, such as zhuangbility.

It seems that use of transliteration or Chinese pinyin to produce $\mathrm{CEV}$ is an emerging trend (Table 1). As has been discussed in the last section, there is generally no inflection for the transliterations, which are always used in their original form, with respect to expression of grammatical categories, such as tense and number. The formal stability of the transliterations might be due to the interference of the Chinese language. In Chinese, all characters are used in their original form all of the time and all grammatical meanings are implied or expressed via lexical devices instead of inflections.

It has been observed that the spelling of transliterations is not consistent in some texts. For example, tuhao is sometimes spelt as Tuhao and sometimes as tuhao, even in the same text. It is assumed that there is no need to capitalize tuhao because it is not a proper noun. As for the widespread use of transliterations, there are at least two strengths for their use, i.e. representation of Chinese characteristics and conciseness in expression. All of the transliterations, such as nongmingong, retain the phonetic features of Chinese words, thus giving the writing an exotic flavor. Some Chinese words and expressions are rich in connotation, such as santong (三通), and use of transliteration can achieve economy in linguistic expression. But there is a problem with the English transliteration of Chinese words, i.e. the meaning of transliterated words is not clear. Therefore, it is often seen that a paraphrase in various forms is used when a transliterated word appears for the first time.

Many literal translations may be somewhat unintelligible because their meaning is not on the surface. For example, Vegetable Basket Project is not a project for manufacturing vegetable baskets but one for increasing the production of vegetables, fruits, eggs, meat and other foodstuffs in order to eliminate food shortages; Hope Project is not a project full of hopes but one for building a primary school in order to provide education for poor children who are regarded as the hope for the future in China; human flesh search does not mean a search via human flesh nor a search for human flesh but a massive online search. Due to the semantic obscurity of some literal translations, an additional explanation is often seen with them. For example, the explanation between the dashes in example (15) can be viewed as an informal definition of 'human flesh search', resulting in English readers' immediate understanding of the expression.

(15) Her high-sounding words eventually sparked one of China's infamous 'human flesh search' - a cyber manhunt that ferrets out a person's most intimate details about his private life - by computer geeks.

Occasionally, a literal translation may be ungrammatical, as in Three Represents, which is the literal rendering of the Chinese political term 三个代表. It is the basic guideline of the Communist Party of China and its specific content goes as follows: 
- The Party must always represent the development trend of China's advanced productive forces.

- The Party must always represent the orientation of China's advanced culture.

- The Party must always represent the fundamental interests of the overwhelming majority of the Chinese people.

The above guideline contains three instances of represent, which is perhaps the reason for the creation of the characteristic expression Three Represents, even though the verb represent cannot be used as a noun, put after three and followed by the inflectional marker $-s$ to indicate the plural. Two other problems with CEV are that the combination of literal translation and transliteration sometimes makes CEV nothing-like and some free translations are too long to look like a word or a phrase.

Nevertheless, CEV plays an irreplaceable role in introducing China's government policy, social phenomena and traditional culture. Use of literal renderings, transliterations and even Chinese characters in China-related English reporting and English translation of Chinese classics shows the growing cultural confidence of Chinese writers and translators as well as China's economiccultural impact on English writers and translators. In China the craze for graduate school helps disseminate the neologisms in the China Daily website corpus among those who will take the entrance examination for postgraduate schools, especially for the Master of Translators and Interpreters (Qiu, 2014). At present, the Chinese government is advancing the campaign of Chinese culture 'going global' and the fast development of China's economy gives rise to an increasing zeal among foreigners to learn Chinese language and culture. These two forces will combine, creating strong momentum to constantly increase the Chinese characteristics of CEV in the future.

\section{Conclusion}

As a major source for the production of CEV, the China Daily website has created a large number of neologisms via transliteration, literal translation, free translation and other translating methods. These new words play a crucial role in introducing China's government policy, social phenomena and Chinese culture. Transliteration of Chinese words has become an emerging trend in producing $\mathrm{CEV}$. Although there are some problems with the usage of CEV, they carry a strong Chinese flavor and represent writers' growing cultural awareness.

\section{Note}

1 See http://www.chinadaily.com.cn/language_tips/trans/ trans_collect.html.

\section{References}

Bolton, K. \& Graddol, D. 2012. 'English in China today.' English Today, 28(3), 3-9.

Botha, W. 2014. 'English in China's universities today.' English Today, 30(1), 3-10.

Cai, Y. 2014. 'On English translation of “tuhao" (土豪).' Journal of Zhanjiang Normal University, 35(5), 131-4.

Chinadaily.com. 2014. 'Chinese buzzwords popular on Urban Dictionary.' Online at $<$ http://www.chinadaily. com.cn/china/2014-04/18/content_17446790.htm> (Accessed August 9, 2015).

Du, L. \& Zhang, R. 2012. 'Innovations in the construction projects of the China Daily website.' Chinese Newspaper Industry, 15(7), 17-19.

Eaves, M. 2011. 'English, Chinglish or China English? Analysing Chinglish, Chinese English and China English.’ English Today, 27(4), 64-70.

Gui, T. 2013. "Tuhao" and "dama" will enter into the Oxford Dictionary.' Beijing Youth Daily, November 14, B03.

He, C. \& Xiao, Y. 2003. 'Brand name translation in China: An overview of practice and theory.' Babel, 49(2), 131-48.

Hu, X. B. 2016. 'Keep off the grass? No way!.' English Today, 32(1), 21-7.

oxforddictionaries.com. 2015. 'Oxford Dictionaries: Language matters.' Online at $<$ http://www.oxford dictionaries.com/spellcheck/english/?q=tuhao $>$ (Accessed August 6, 2015).

Pinkham, J. 2000. The Translator's Guide to Chinglish. Beijing: Foreign Language Teaching and Research Press.

Qiu, D. 2014. 'Some more remarks on the translation of Chinese neologisms: Problems with the English translation of neologisms at the China Daily website.' Chinese Translators Journal, 35(6), 90-2.

Zhou, W. \& He, F. 2015. 'On translation of Chinese neologisms "tuhao" and "dama" from the perspective of pragmatics.' Journal of Hengyang Normal University, 36(5), 129-31. 